\title{
NiAl Precipitation in Delta Ferrite Grains of 17-7 Precipitation-hardening Stainless Steel During Low- temperature Interstitial Hardening
}

\author{
D. Wang, H. Kahn, F. Ernst, and A. H. Heuer \\ Department of Materials Science and Engineering, \\ Case Western Reserve University \\ 10900 Euclid Avenue, Cleveland, OH, 44106, USA
}

\begin{abstract}
:
Interstitial hardening via low-temperature carburization and nitridation has been studied in 17-7 precipitation-hardening stainless steel. During such interstitial hardening, nanometer-scale NiAl precipitates form in delta ferrite in the bulk, but not in the hardened surface layer. In the carburized ferrite grains, regions of NiAl stoichiometry could be identified, but cannot be identified as regions with a different crystal structure. In the nitrided grains, $\mathrm{NiAl}$ particles could neither be detected by corresponding changes in local composition nor by their crystal structure.
\end{abstract}

Keyword: NiAl precipitation; low-temperature carburization; low-temperature nitridation; atom probe tomography; transmission electron microscopy. 
Precipitation-hardening (PH) stainless steels are a family of stainless steels that combine high strength, ductility, and good corrosion resistance. They are widely used as structural materials in various industrial applications. Depending on the thermal history, alloys can contain variable amounts of austenite, ferrite, and martensite. Precipitation hardening in these steels is achieved by homogeneously dispersed fine precipitates formed during aging.

PH stainless steels containing $\mathrm{Ni}$ and $\mathrm{Al}$ (like 17-7 and 13-8 Mo) can be agehardened by the formation of NiAl particles (space group Pm $\overline{3} m$ ). The lattice parameter

of stoichiometric NiAl at room temperature is $0.2887 \mathrm{~nm}$, which is very close to the lattice parameter of the ferrite matrix $(0.2881 \mathrm{~nm}$ in this study). The aging temperature of $17-7 \mathrm{PH}$ stainless steel is above $773 \mathrm{~K}$ [1].

Age hardening by $\mathrm{NiAl}$ was studied previously in several stainless steels. In the initial stage of NiAl precipitation, there are significant fractions of $\mathrm{Cr}$, $\mathrm{Mo}$, and $\mathrm{Fe}$ present in the precipitates [2-6]. As aging proceeds, the fractions of $\mathrm{Ni}$ and $\mathrm{Al}$ increases and the Ni-to-Al ratio approaches unity [2,3]. The NiAl precipitates are nanometer-sized, spherical, and coherent with the ferrite- or martensite matrix [6].

Low-temperature carburization or nitridation are effective ways to improve surface properties and corrosion resistance of stainless steels [7-13]. For PH 13-8 Mo stainless steel, a significant increase of surface hardness and corrosion resistance was 
achieved after low-temperature carburization [13]. Interestingly, a thin carbidic layer formed on the carburized surface. However, there was no report of NiAl formation.

Low-temperature carburization and nitridation have also been successfully applied to 17-7 PH stainless steel $[14,15]$. The ferrite phase in the alloy responds to such interstitial hardening in a very unique and unusual manner, leading to a weak-contrast appearance in conventional transmission electron microscopy (TEM) images. Nanometer-scale NiAl precipitates were observed in the ferrite grains in the bulk but absent in the weak-contrast grains [14].

In the present work, we investigate the effect of low-temperature carburization and nitridation on the formation of NiAl precipitates in the ferrite phase of 17-7 $\mathrm{PH}$ stainless steel.

17-7 PH stainless steel in condition A [1] was provided by AK Steel in the form of $3 \mathrm{~mm}$ thick plates. The nominal composition is $17-19$ at. $\% \mathrm{Cr}, 6.5-7.1$ at. $\% \mathrm{Ni}, 2$ at.\% $\mathrm{Al}, \leq 1.0$ at. $\% \mathrm{Mn}, \leq 2.0$ at. $\% \mathrm{Si}, \leq 0.4$ at. $\% \mathrm{C}$, and balance $\mathrm{Fe}$. All samples were electropolished before low-temperature carburization and nitridation. 17-7 PH stainless steel in condition A is semi-austenitic and contains austenite, martensite, and residual delta ferrite (formed during solidification). Gas-phase double-activation low-temperature carburization was carried out at $653 \mathrm{~K}$ for 146 hours by the Swagelok Company using $\mathrm{HCl}$ gas in situ in the activation step to remove the spontaneously formed $\mathrm{Cr}_{2} \mathrm{O}_{3}$-rich passive film. Carbon monoxide gas was used as the carbon source during carburization 
[16]. Nitrided samples were also doubly activated in $\mathrm{HCl}$ and then treated at $713 \mathrm{~K}$ in a flowing gaseous mixture of $\mathrm{NH}_{3}(0.35 \mathrm{~L} / \mathrm{min})$ and $\mathrm{H}_{2}(0.63 \mathrm{~L} / \mathrm{min})$ for 20 hours. This work was done by a J4915 carburization furnace manufactured by CVD Equipment Corporation.

TEM samples were prepared using a FEI Nova Nanolab 200 dual-beam focused ion beam/scanning electron microscope (FIB/SEM) from finely polished cross sections of carburized and nitrided 17-7 PH stainless steels. A FEI Tecnai F30 (300 kV) and a Zeiss Libra 200EF $(200 \mathrm{kV})$ were used to acquire TEM data. Specimens for atom probe tomography (APT) were prepared from the same cross-sectioned samples of carburized or nitrided 17-7 PH stainless steels by the FIB lift-out technique using a FEI Helios dualbeam FIB/SEM. APT data was acquired on a Cameca 4000 HR Atom Probe, operated in laser mode with $20 \mathrm{pJ}$ laser power at a temperature of $50 \mathrm{~K}$. As is common for APT analyses, the atom counting efficiency was limited to about $50 \%$ [17].

Two APT samples were prepared and analyzed from two ferrite grains of crosssectioned nitrided 17-7 PH stainless steel. One is from the bulk material and the other is from the nitrided layer (case). (The nitrogen concentration is about 19 at.\% at the free surface, falling to essentially zero at the case-core interface [15].) The nitrogen concentration of the ferrite grain in the bulk sample is less than 0.1 at. $\%$.

A three-dimensional (3D) atom map of $\mathrm{Al}$ was acquired from a ferrite grain from the bulk material. Fig. 1a shows the Al map with 12 at.\% isoconcentration surfaces 
superimposed, implying possible $\mathrm{Al}$ segregation in the ferrite grain. (The value of 12 at.\% represents an arbitrary choice, which clearly exposes clustering. While different choices will alter the apparent particle size, the observation of clustering as such is independent of the threshold value.) A proximity diagram (proxigram) (Fig. 1b) obtained from the 12 at.\% $\mathrm{Al}$ isoconcentration surfaces shows that clusters have a Ni-to-Al ratio of 1, but still possess significant fractions of Fe and Cr. The cluster count analysis (Fig. 1c) positively identified the formation of NiAl particles in the ferrite during nitridation; this involved demonstrating that the Al-Ni cluster distribution (number of clusters counted at certain cluster diameter) deviates significantly from a random cluster distribution.

Even though optimum aging of 17-7 PH stainless steel requires heat treatment at $\approx 773 \mathrm{~K}$ for $1 \mathrm{~h} \mathrm{[1]}$, the nitriding temperature $(713 \mathrm{~K}$ ) used in this study is high enough to induce NiAl precipitation, given the prolonged exposure time of 20 hours. As suggested by the proxigram, the size of $\mathrm{NiAl}$ particles is about $4 \mathrm{~nm}$ and the interface between the particles and the ferrite matrix is not well-defined, indicating the precipitation is still at an early stage.

Ferrite grains in the nitrided alloy were also studied by TEM, as shown in Fig. 2a. Two different types of ferrite grains were revealed: a weak-contrast ferrite grain in the case (the square region) and a ferrite grain in the bulk material (the circular region). Two diffraction patterns from a $\langle 011\rangle_{\text {bcc }}$ zone axis were obtained from these two ferrite grains, as shown in Figs. 2d and 2e, respectively. 
A diffraction pattern acquired from the ferrite grain from the bulk material of the nitrided sample is shown in Fig. $2 b$ (viewing along the $<011\rangle_{\mathrm{bcc}}$ zone axis). In addition to the strong matrix reflections, there are weak reflections in the diffraction pattern. As compared to Fig. 2c (acquired from a ferrite grain in as-received alloy), the extra reflections indicate the presence of a second phase in the ferrite grain. In Fig. 2b, extra reflections are observed at half reciprocal spacings of the $(002)_{\mathrm{bcc}}$ reflections. These extra reflections are consistent with simple-cubic NiAl. Further weak reflections are observed, probably because of double diffraction.

Although NiAl particles form in the ferrite grains in the bulk material during lowtemperature carburization or nitridation, $\mathrm{NiAl}$ cannot be readily observed in the nearsurface carburized or nitrided weak-contrast ferrite grains. This is apparent by the absence of $\mathrm{NiAl}$ reflections in all the diffraction patterns acquired from weak-contrast grains after both low-temperature carburization and low-temperature nitridation $[14,15$, $18]$.

A diffraction pattern (Fig. 2e) from a ferrite grain undergoing transformation to a weak-contrast appearance deeper in the case shows diffuse streaks along $[001]_{\mathrm{bcc}}$ directions and no sign of any nitride formation, indicating that it is at an early stage of weak-contrast ferrite formation [14]. However, this diffraction pattern is significantly different from the one obtained from the original ferrite grain in the bulk material shown in Fig. 2b, i.e. the reflections from $\mathrm{NiAl}$ are diffuse, implying a possible disordering of $\mathrm{NiAl}$ during nitridation (given the fact that $\mathrm{NiAl}$ reflections were observed in other ferrite 
grains from the bulk material under otherwise similar imaging condition). In the diffraction pattern from the weak-contrast nitrided ferrite grain (Fig. 2d), extra reflections due to NiAl, if present, are below the detection limit. TEM should easily detect a volume fraction as small as 0.1 vol. \% for particles of this size. Instead, reflections due to nitride formation were observed [18]. This indicates that the NiAl particles either dissolved in the weak-contrast ferrite or never formed. Given a prolonged heat treatment, the ferrite grain undergoing transformation could eventually become a weak-contrast grain. In carburized weak-contrast ferrite grains, all diffraction patterns conform to a bcc structure, and extra reflections that arise from $\mathrm{NiAl}$ are absent [14].

NiAl precipitation was further investigated by APT in nitrided and carburized weak-contrast ferrite grains. Fig. 3a shows a 3D Al atom map of a nitrided sample, superimposed with 7.5 at.\% $\mathrm{Al}$ isoconcentration surfaces. The proxigram of these clusters (Fig. 3b) shows Al-enriched clusters with no corresponding Ni enrichment (the Ni:Al ratio 3: 13) (2.8 at.\% vs 13.1at.\%)). NiAl cluster analysis of a nitrided ferrite grain (Fig. 3c) show a random $\mathrm{Ni}-\mathrm{Al}$ distribution within the ferrite, indicating that there are no $\mathrm{NiAl}$ clusters in the nitrided ferrite. This is in a good agreement with the TEM results shown earlier, in that extra reflections attributed to NiAl formation were absent from nitrided weak-contrast ferrite grains.

In the carburized weak-contrast ferrite grains, although there is no diffraction evidence of NiAl formation in TEM, NiAl was positively identified by the proxigram (Fig. 4b, the Ni:Al ratio 3.1:4.7 (15.5 at.\% vs 23.5 at.\%) and cluster analysis (Fig. 4c). 
Within the Al-enriched clusters, there is a corresponding Ni enrichment but the Al-to-Ni ratio is less than unity.

$\mathrm{NiAl}$, as the precipitation-hardening phase, has a formation energy of about 120 $\mathrm{kJ} / \mathrm{mol}$ [19]. The as-received samples were in condition A, i.e. no aging had been carried out, and thus no NiAl precipitates were present (confirmed by Fig. 2c). However, NiAl nanoparticles $(<4 \mathrm{~nm})$ were positively identified in the ferrite grains from the bulk material after both carburization and nitridation. This is unexpected because the aging temperature of this alloy is about $773 \mathrm{~K}$, considerably higher than the processing temperatures of low-temperature carburization (653 K) and nitridation (713 K). However, after long exposures, e.g. 150 hours for carburization, a significant density of NiAl nuclei was detected. The NiAl clusters identified by APT show a 1:1 Ni-to-Al ratio, although an appreciable fraction of $\mathrm{Fe}$ and $\mathrm{Cr}, \approx 25$ at.\%, is present.

After carburization, extra reflections due to $\mathrm{NiAl}$ precipitation were observed in ferrite grains in the bulk material. Uniform precipitate size and uniform spatial distributions in the ferrite grains in the bulk material, but not in the weak-contrast ferrite grains, were previously confirmed by dark-field TEM images [15]. This is consistent with the absence of the extra reflections in the weak-contrast grains, suggesting dissolution of NiAl precipitates. Even though the APT data still suggests the presence of the NiAl clusters in weak-contrast ferrite, there is no evidence of its presence in the diffraction data, indicating the NiAl particles must disorder during weak-contrast ferrite grain formation. 
Under carbon paraequilibrium conditions, carbon and Al mutually lower the activity coefficients in the carbon-supersaturated solid solution [20], thus increasing the solubility of $\mathrm{Al}$ in ferrite. This is similar to the interaction between carbon and $\mathrm{Cr}$ in austenite [21]. This destabilizes NiAl clusters and can explain the observed disordering, dissolution, or suppression of precipitation in the ferrite matrix.

One further possibility to explain the observations is to assume that the NiAl clusters are deformed by dislocations generated during weak-contrast ferrite formation. Such fragmentation of the NiAl clusters can possibly lead to dissolution due to capillarity effects [22]. This can explain the NiAl composition observed by APT in carburized ferrite grains, i.e. the composition no longer has a 1:1 Ni-to-Al ratio. Since the diffusion coefficient of $\mathrm{Ni}$ at the carburizing temperature $(653 \mathrm{~K})\left(4.2 \times 10^{-24} \mathrm{~m}^{2} / \mathrm{s}\right.$ [23]) is much lower than that at nitriding temperature $(713 \mathrm{~K})\left(1.9 \times 10^{-22} \mathrm{~m}^{2} / \mathrm{s}[23]\right)$, it is difficult for Ni to diffuse out of the NiAl clusters during carburization.

The dissolution of NiAl during low-temperature nitridation has a similar explanation. However, the absence of $\mathrm{NiAl}$ reflections in the nitrided weak-contrast ferrite grains is consistent with the random distribution of $\mathrm{Ni}$ and $\mathrm{Al}$ in solid solution revealed by APT data. A diffraction pattern acquired from a ferrite grain undergoing transformation (Fig. 2e) shows diffuse NiAl reflections as well as diffuse streaks along a $[001]_{\text {bcc }}$ direction, suggesting that disordering of NiAl clusters occurs during lowtemperature nitridation. 
The presence of interstitial nitrogen destabilizes NiAl clusters. The $\mathrm{Al}$ in the intermetallic $\mathrm{NiAl}$ could later combine with nitrogen to form $\mathrm{MN}$ nitride ( $\mathrm{M}$ being $\mathrm{Fe}, \mathrm{Cr}$, and $\mathrm{Al})[18,24]$, due to a much higher formation energy of AlN ( $<-200 \mathrm{~kJ} / \mathrm{mol}[25])$ compared to that of $\mathrm{NiAl}$.

During nitridation, $\mathrm{NiAl}$ nucleated as small clusters in the ferrite at the nitriding temperature. But as nitrogen diffuses to the ferrite, due to the limited nitrogen solubility in this phase, nitrides tend to form. Since nitrides are much more stable than the NiAl formed earlier, the nitrogen can extract the $\mathrm{Al}$ from $\mathrm{NiAl}$ intermetallics and form $\mathrm{AlN}$, causing decomposition of NiAl. Therefore, in a diffraction pattern from a ferrite grain in transition to the weak contrast state, reflections from NiAl become diffuse (Fig. 2e) and eventually disappear and are replaced by nitride reflections in fully nitrided weakcontrast ferrite grain (Fig. 2d).

The observation that NiAl cannot be identified compositionally after nitridation can be attributed to a higher nitridation temperature $(713 \mathrm{~K})$ compared to that of carburization $(653 \mathrm{~K})$. Once NiAl becomes destabilized by nitrogen, Ni tends to diffuse out of the original clusters and lower its local chemical potential by homogenization within the grain. This also suggests that the carburization and nitridation were not carried out under ideal paraequilibrium conditions, in which diffusion of substitutional atoms (by definition) is completely suppressed. 
In summary, $\mathrm{NiAl}$, absent in the as-received alloy, precipitates in the ferrite in the bulk of 17-7 PH stainless steel during low-temperature carburization and nitridation. However, in ferrite grains near the carburized and nitrided surfaces, no NiAl precipitates were observed in the same samples conditions. This indicates that $\mathrm{NiAl}$ precipitates that were present in the as-received condition dissolved during the interstitial-hardening. We suggest that the presence of interstitial carbon and nitrogen decreases the activity of $\mathrm{Al}$, and this increases its solubility in the ferrite and induces $\mathrm{NiAl}$ dissolution (or prevents their initial precipitation). Therefore, the aging effect of low-temperature carburization and nitridation and the interaction between interstitial carbon or nitrogen with other alloying components must be taken into consideration, especially for precipitationhardening alloys.

We are grateful for the National Science Foundation (NSF) for financial support, grant No. DMR-1104937, the Swagelok Center for Surface Analysis of Materials at Case Western Reserve University, and the University of Michigan, School of Engineering for the access to the atom probe instrument, and to A. H. Hunter for his assistance.

\section{Reference}

[1] 17-7 PH stainless steel product data bulletin by AK steel.

[2] S.D. Erlach, H. Leitner, M. Bischof, H. Clemens, F. Danoix, D. Lemarchand, I. Siller, Mater. Sci. Eng. A 429 (2006) 96-106.

[3] Z. Guo, W. Sha, D. Vaumousse, Acta Mater. 51 (2003) 101-116.

[4] H. Leitner, M. Schober, r. Schnitzer, Acta Mater. 58 (2010) 1261-1269.

[5] Z.K. Teng, M.K. Miller, G. Ghosh, C.T. Liu, S. Huang, K.F. Russell, M.E. Fine, P.K. Liaw, Script Mater. 63 (2010) 61-64.

[6] D.H. Ping, M. Ohnuma, Y. Hirakawa, Y. Kadoya, K. Hono, Mater. Sci. Eng. A 394 (2005) 285-295. 
[7] G.M. Michal, F. Ernst, H. Kahn, Y. Cao, F. Oba, N. Agarwal, A.H. Heuer, Acta Mater. 54 (2006) 1597-1606.

[8] N. Agarwal, H. Kahn, A. Avishai, G.M. Michal, F. Ernst, A.H. Heuer. Acta Mater. 55 (2007) 5572-5580.

[9] J.P. Hsu, D. Wang, H. Kahn, F. Ernst, G.M. Michal, A.H. Heuer, J. Int. Fatigue 47 (2013) 100-105.

[10] H. Kahn, A.H. Heuer, G.M. Michal, F. Ernst, R. Sharghi-Moshtaghin, Y. Ge, P.M. Natishan, R.J. Rayne, F.J. Martin, Surf. Eng. 28 (2012) 213-219.

[11] D. Wang, H. Kahn, J.J. Lewandowski, F. Ernst, G.M. Michal, A.H. Heuer, Mater. Sci. Eng. A 556 (2012) 43-50.

[12] D. Wu, H. Kahn, J.C. Dalton, G.M. Michal, F. Ernst, A.H. Heuer, Acta Mater. 79 (2014) 339-350.

[13] A.H. Heuer, H. Kahn, L.J. O'Donnell, F. Ernst, G.M. Michal, R.J. Rayne, F.J. Martin, P.M. Natishan, Electrochem. Solid-State Lett. 13 (2012) C37-C39.

[14] D. Wang, C.-W. Chen, J.C. Dalton, F. Yang, R. Sharghi-Moshtaghin, H. Kahn, F. Ernst, R.E.A. Williams, D.W. McComb, A.H. Heuer, Acta Mater. 86 (2015) 193-207.

[15] D. Wang, PhD Dissertation, Case Western Reserve University, 2014.

[16] P.C. Williams, S.R. Collins, JOM 60 (2008) 27-30.

[17] M.K. Miller, A. Cerezo, M.G. Hetherington, G.D.W. Smith, Atom Probe

Field Ion Microscopy, Clarendon Press, Oxford, 1996.

[18] D. Wang, F. Ernst, H. Kahn, A.H. Heuer, Metall. Mater. Trans. A 45 (2014) 35783585.

[19] N.I. Medvedeva, Y.N. Gornostyrev, D.L. Novikov, O.N. Mryasov, A.J. Freeman, Acta Mater. 46 (1998) 3433-3442.

[20] G.M. Michal, F.E. Ernst, A.H. Heuer, Metall. Mater. Trans. A 37 (2006) 1819-1824.

[21] F. Ernst, Y. Cao, G.M. Michal, A.H. Heuer, Acta Mater. 55 (2007) 1895-1906.

[22] J. Languillaume, G. Kapelski, B. Baudelet, Acta Mater. 45 (1997) 1201-1212.

[23] K. Hirano, M. Cohen, B.L. Averbach, Acta Metall. 9 (1961) 440-445.

[24] M.H. Biglari, C.M. Brakman, E.J. Mittemeijer, S. Van der Zwaag, Metall. Mater. Trans. A 26 (1995) 765-776.

[25] H.L. Schick, Thermodynamics of certain refractory compounds, Academic Press, NEW YORK, 1966. 


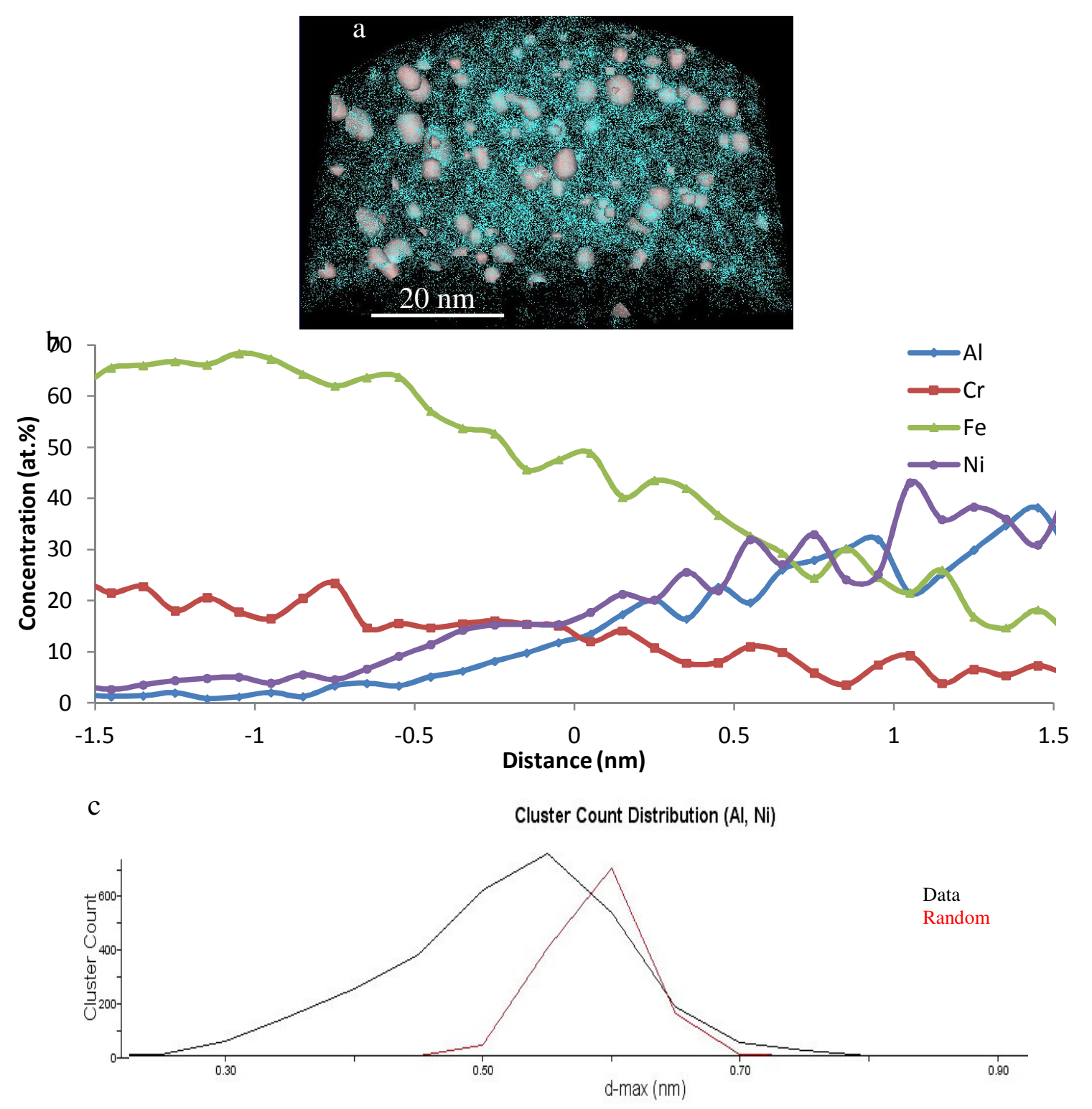

Fig. 1 (a) 3D Al atom map in a ferrite grain from the bulk material, superimposed with 12 at.\% $\mathrm{Al}$ isoconcentration surfaces. (b) Proxigram of 12 at.\% Al clusters. (c) Cluster count distribution analysis between $\mathrm{Al}$ and $\mathrm{Ni}$. 


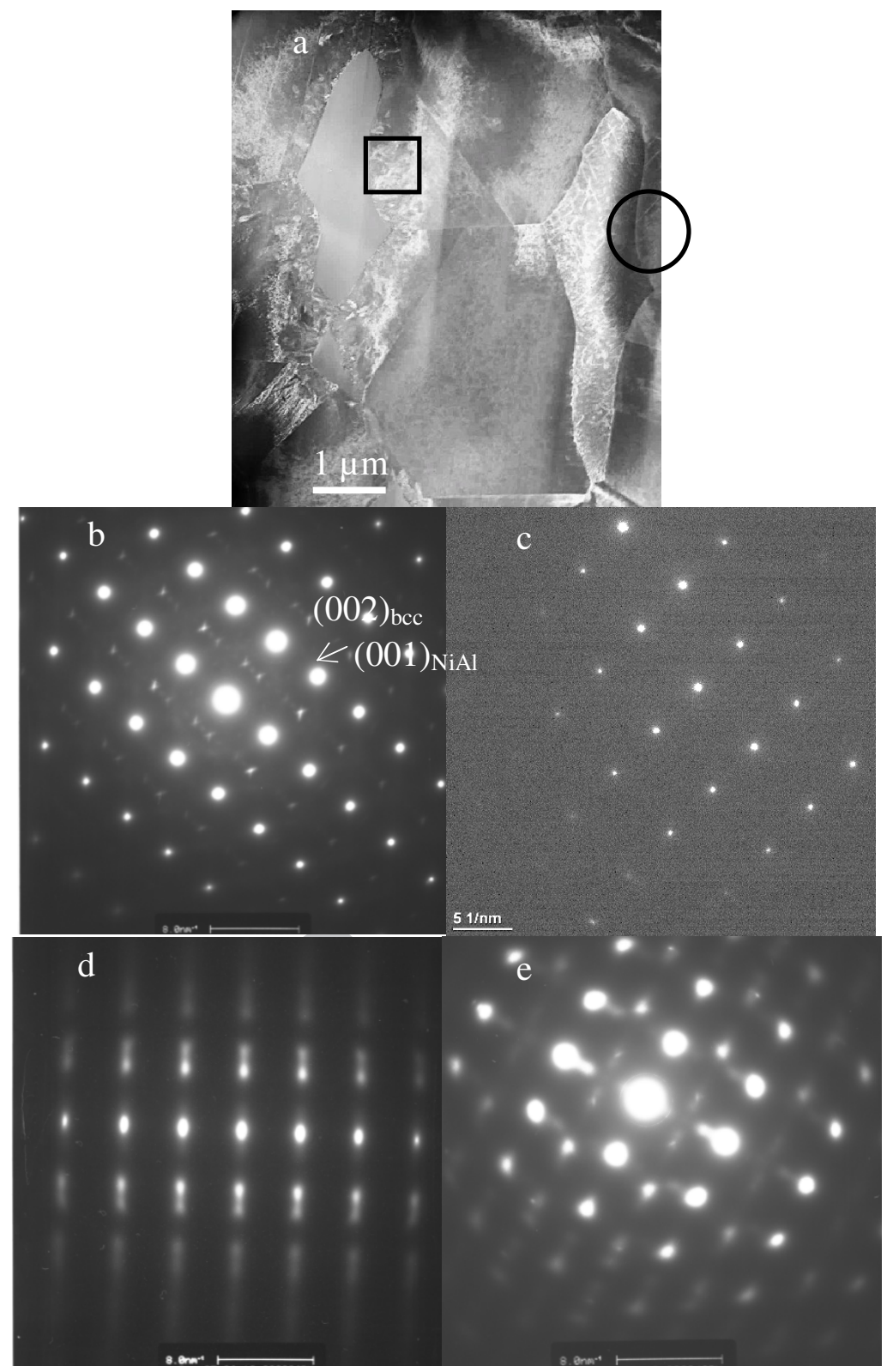

Fig. 2 (a) Scanning TEM (STEM) image of a cross-sectioned foil nitrided at $713 \mathrm{~K}$. The image was acquired with a HAADF detector with a camera length of $1.44 \mathrm{~m}$, implying multi-beam dark-field imaging producing diffraction contrast. The free surface in this image is about $5 \mu \mathrm{m}$ to the left. (b) and (c) Diffraction patterns acquired from delta ferrite grains deep in the bulk material and as-received material. (d) and (e) Diffraction patterns acquired from the squared and circled regions in (a), respectively. 

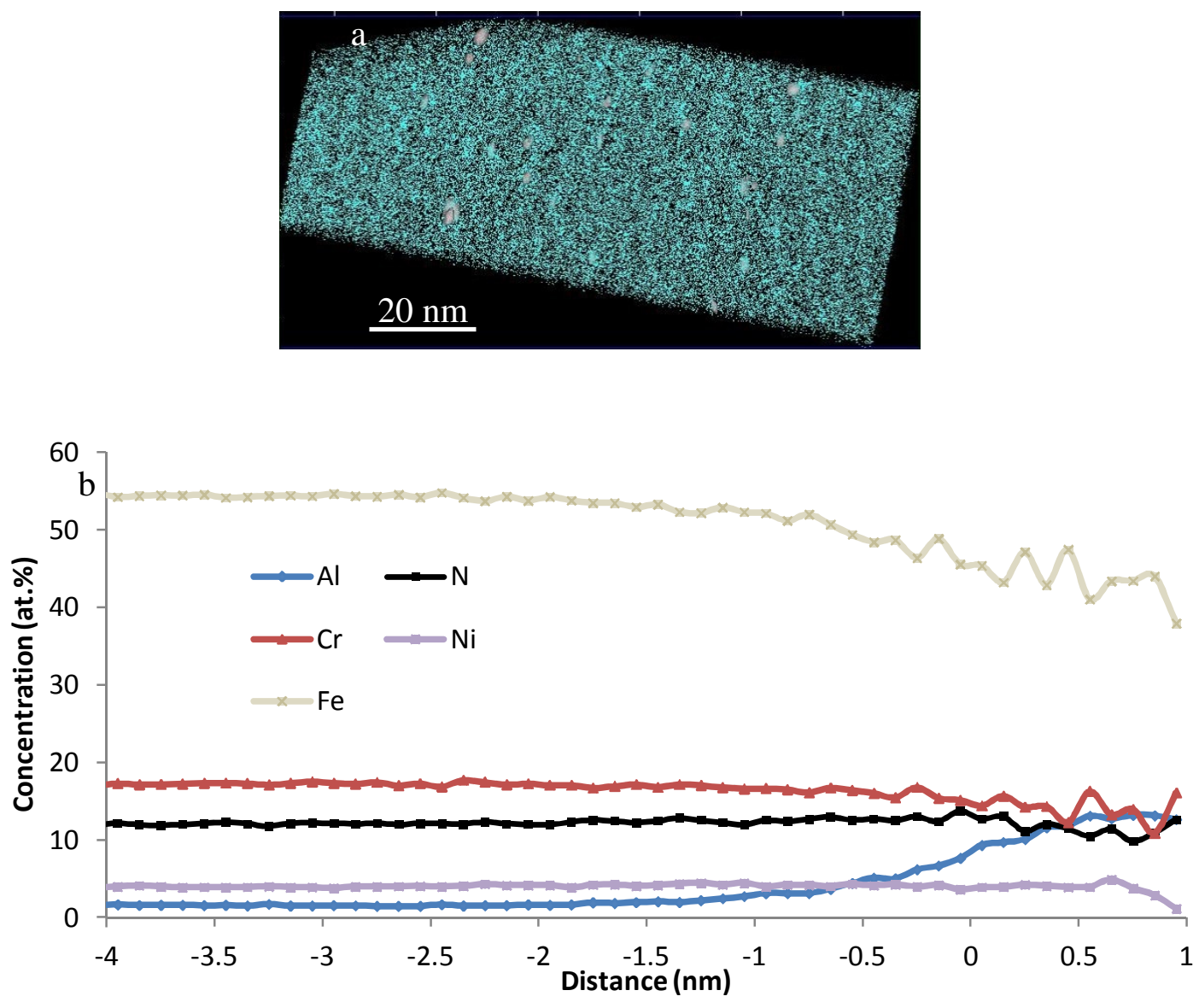

Cluster Count Distribution (Al, Ni)

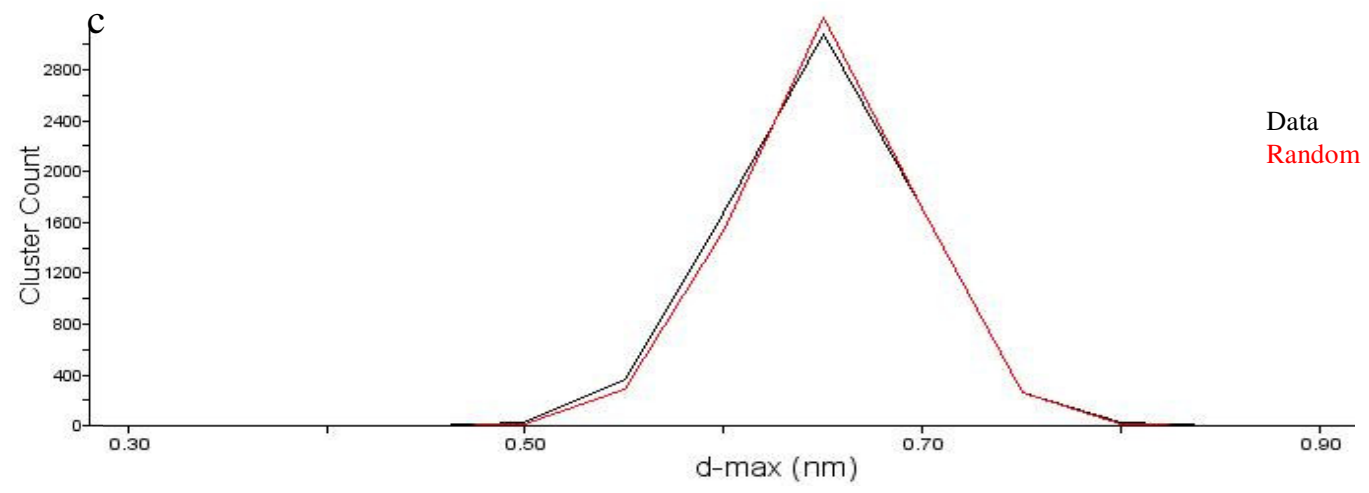

Fig. 3 (a) 3D Al atom map of a nitrided ferrite grain superimposed by 7.5 at.\% $\mathrm{Al}$ isoconcentration surfaces (grey), (b) proxigram of these clusters, and (c) NiAl cluster count distribution analysis. 


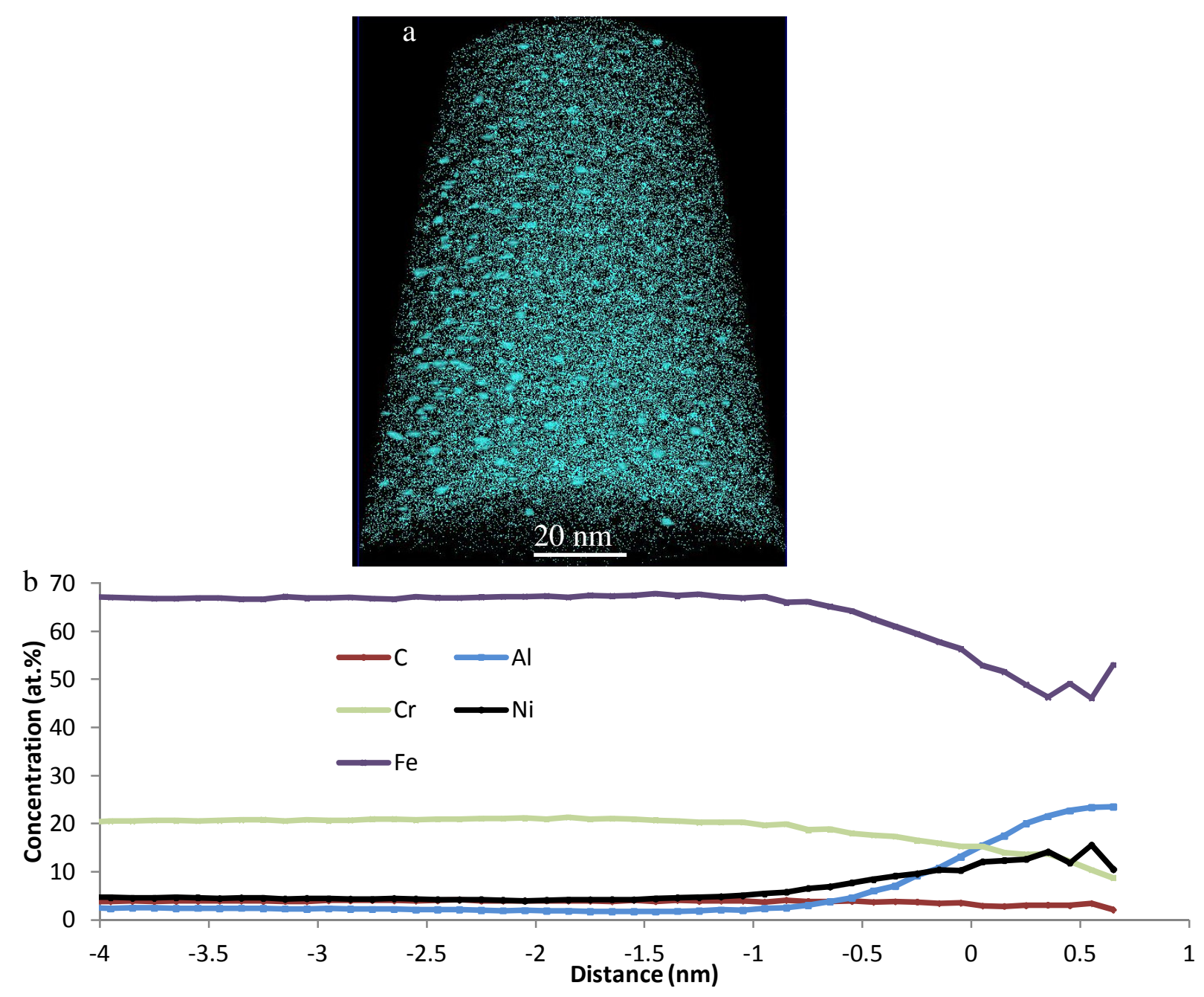

c

Cluster Count Distribution (AI, Ni)

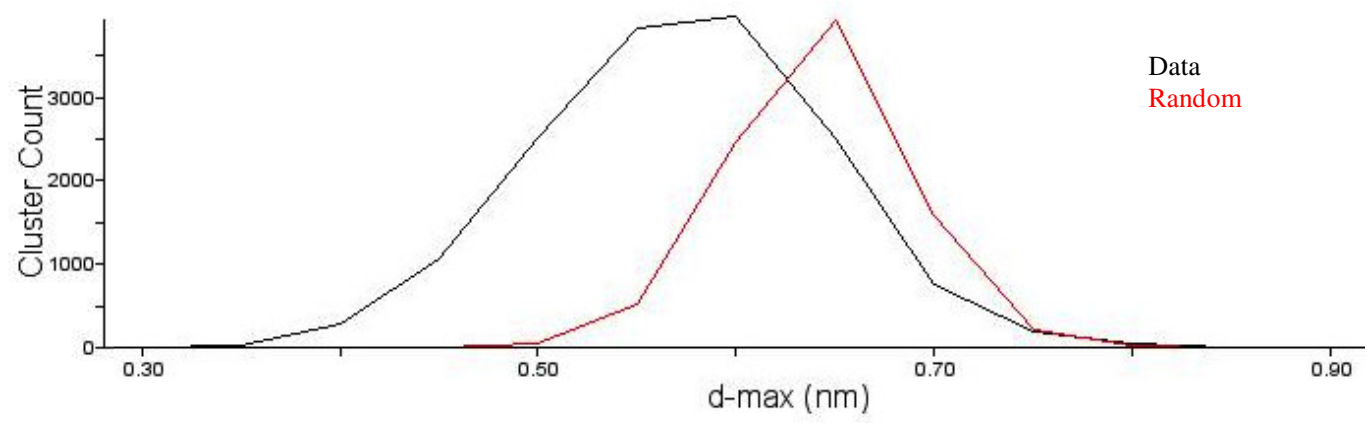

Fig. 4 (a) 3D Al atom map of a carburized weak-contrast ferrite grain superimposed by 13 at.\% $\mathrm{Al}$ isoconcentration surfaces, (b) proxigram of these isoconcentration surfaces, and (c) NiAl cluster count analysis in the carburized ferrite grain. 
NiAl precipitation in delta ferrite of 17-7 Precipitation-hardening stainless steel bulk material and nitrided surface layer

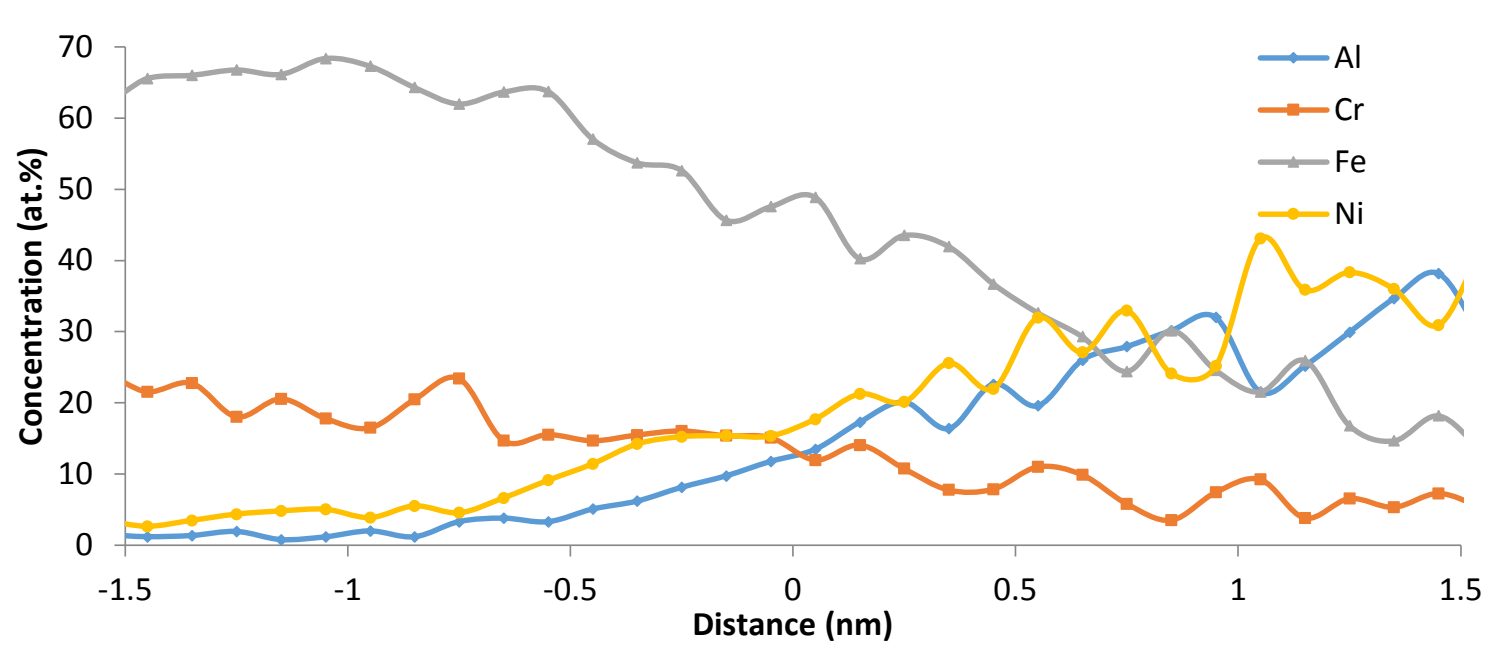

Cluster Count Distribution (Al, Ni)

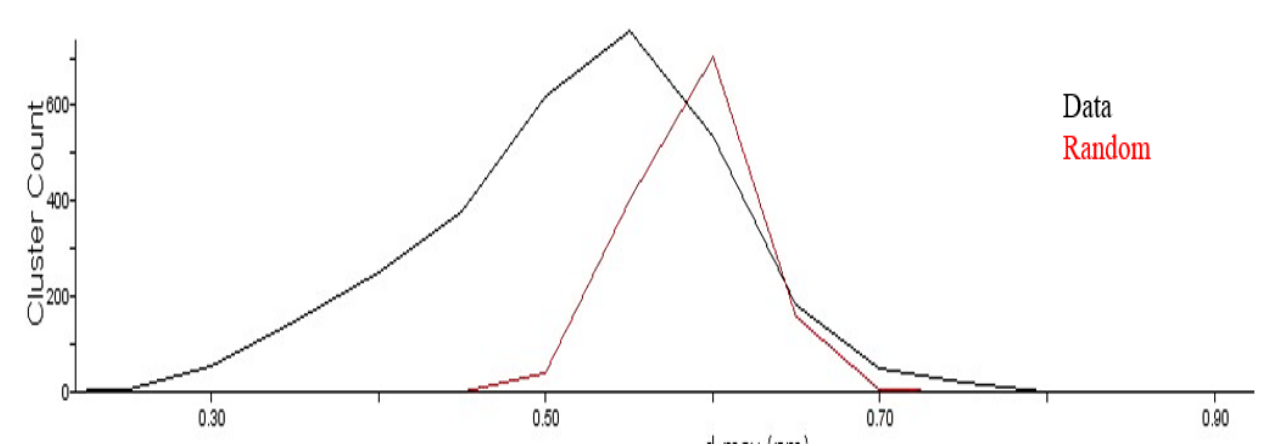

60

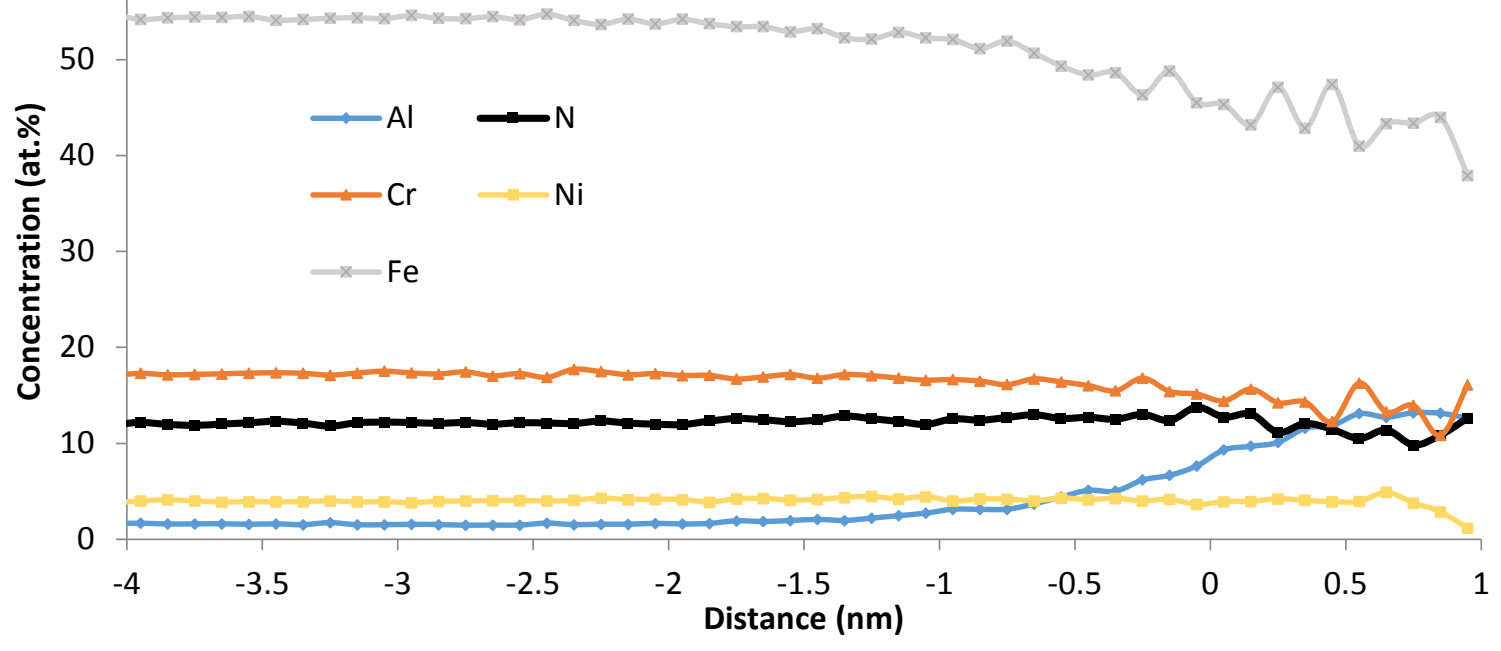

Cluster Count Distribution (Al, Ni)

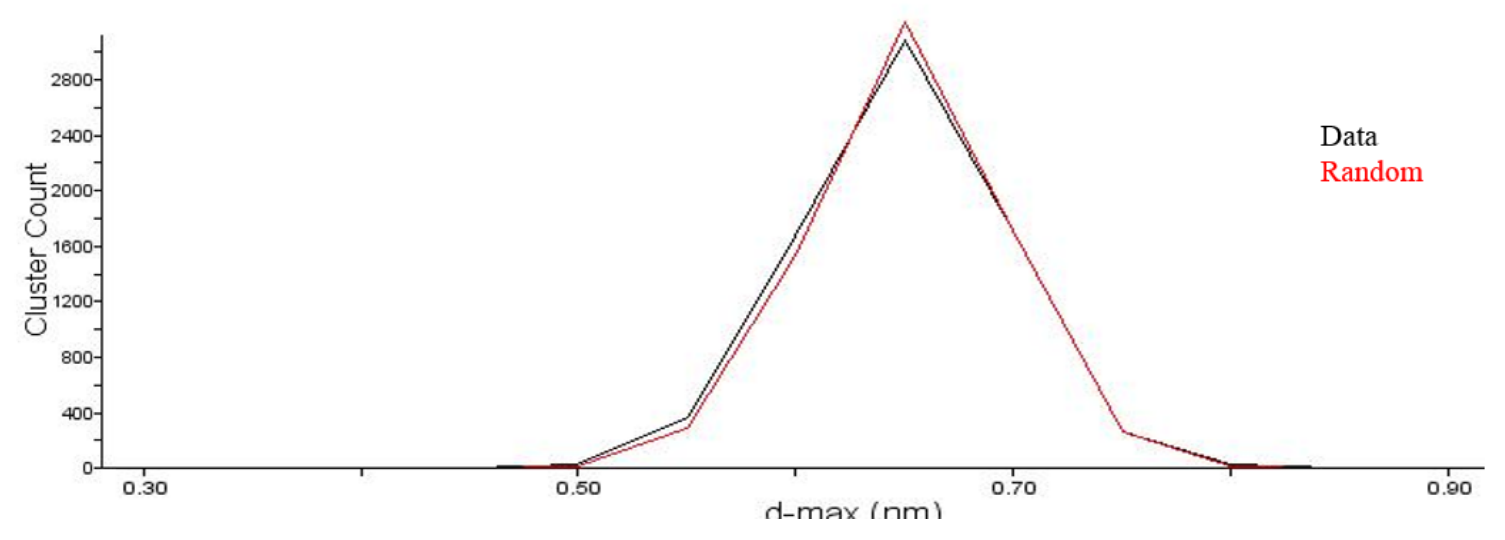

